\title{
A Laboratory-based Experiment on the Efficacy of Graphitic Carbon Nitride Doped with Tungsten Chloride in the Purification of Industrial Wastewater through Degradation of Organic Dye Pollutant
}

\author{
Sheila Moraa Ngare (Corresponding author) \\ College of Environmental Science and Engineering, Tongji University, China \\ E-mail: moraasheila90@gmail.com
}

Juliet Nzula

Kenyatta University, School of Business

P.O. Box 43844-00100, Nairobi Kenya

Donde Oscar Omondi

Egerton University, Department of Environmental Science

P. O. 536-20115, Egerton Kenya

Received: February 11, 2019 Accepted: February 22, 2019 Published: April 19, 2019

doi:10.5296/emsd.v8i2.14328 URL: https://doi.org/10.5296/emsd.v8i2.14328

\begin{abstract}
Water is an essential commodity whose quantity and quality needs to be secured for easier accessibility at both the industrial, public and household levels. However, its availability in adequate quality and quantity has continued to decline worldwide. Indeed, rise in human population coupled with the climate change phenomena have greatly impacted on the quality of water resources through increased organic and inorganic pollution. Rhodamine $\mathrm{B}(\mathrm{RhB})$ dye is a common organic pollutant majorly in industrial wastewater and with numerous environmental and human health effects. The application of graphitic carbon nitride (G-C3N4) in the purification of industrial wastewater to enhance the removal of $\mathrm{RhB}$ is a technology of interest to most environmental quality regulators and agencies. The study was therefore
\end{abstract}


aimed at investigating the performance of graphitic carbon nitride doped with tungsten chloride in the degradation of organic dye pollutant rhodamine B dye from industrial wastewater. The study showed that the as-prepared hybrid photo catalyst exhibits an improved photo degradation performance because of its synergetic effect. Indeed, the photo excited electrons from $\mathrm{g}-\mathrm{C}_{3} \mathrm{~N}_{4}$ were able to efficiently separate and are injected to the conductive band of $\mathrm{WO}_{3}$. The optimum photo activity occurred at the optimum ratio of $0.25 \mathrm{WO}_{3} / \mathrm{g}-\mathrm{C}_{3} \mathrm{~N}_{4}$. There was also stability and efficiency within the hybrid catalyst within the photo degradation process. Indeed, the composite indicates a high activity for degradation of $\mathrm{RhB}$ under visible light irradiation. The presence of $\mathrm{g}-\mathrm{C}_{3} \mathrm{~N}_{4}$ proved to be beneficial for enhancement in photo catalytic activity of the $\mathrm{g}-\mathrm{C}_{3} \mathrm{~N}_{4}-\mathrm{WO}_{3}$ composite and proved to be one of the best alternative modes of $n$ the degrading organic dye pollutant Rhodamine $\mathrm{B}$ dye from wastewater.

Keywords: Graphitic carbon nitride, Photo degradation, Photo catalytic activity, Purification, Wastewater

\section{Introduction}

Water is an essential commodity whose quantity and quality needs to be secured for easier accessibility at both the industrial, public and household levels (Boniface and Mwangi, 2002). The availability of water in adequate quality and quantity have continued to decline worldwide. Indeed, rise in human population coupled with the climate change phenomena have greatly impacted on the quality of water resources (U.S. Global Change Research Program, 2016). Most drinking water sources are increasing getting polluted by both the organic and inorganic materials (Rop et al., 2016). The organic pollutants can be in chemical, biological or physical (Rop et al., 2014; Ekevwe et al., 2017). The pollutants not only degrade the quality of water but also cause consequential impact on human health as well as other animals that are consumed by man (Donde et al., 2014). The increased pollution of drinking water sources has created a worldwide clean water shortage and quality catastrophe, a situation that needs advanced and efficient water treatment techniques for improved safety of water for domestic use (Pang et al., 2016; Donde et al., 2018). Most chemical methods for removal of organic pollutants in waste water have proved to have an ecological and an overall environmental significance (REF). Conventional methods such as absorption, coagulation and use of membranes for depleting organic pollutants in wastewater have proved to be less effective considering that they still leave remnants, generate secondary pollutants and suffer from a high operation cost (Sielechi et al., 2010).

Rhodamine $\mathrm{B}(\mathrm{RhB})$ is an organic pollutant common in industrial wastewater, it contains four $\mathrm{N}$-ethyl groups at either side of the xanthene ring. It can be in the form of liquid, dry powder or wet solid. It is always reddish violet powder or green crystals and strongly fluorescent when diluted in water. It has a molecular weight of $479.01034 \mathrm{~g} / \mathrm{mole}$, molecular formula of $\mathrm{C}_{28} \mathrm{H}_{31} \mathrm{CIN}_{2} \mathrm{O}_{3}$ and a covalent-bonded unit count of 2 (Ping et al., 2017). The organic RhB is an important representative of xanthene dye, widely used as a colorant in textiles and food stuffs, and is also a well-known water tracer fluorescent, which has the property of carcinogenicity, reproductive and developmental toxicity, neurotoxicity, and chronic toxicity towards humans 
and animals (Sun and yang, 2017). The use of graphitic carbon nitride (G-C3N4) has been applied in the purification of wastewater to enhance the removal of $\mathrm{RhB}$ in wastewater (Zhang et al., 2015). G- $\mathrm{C}_{3} \mathrm{~N}_{4}$ has a large band gap which makes it suitable for photolytic reactions and photo catalysis. It is one of the most stable allotropes that is preferred in the splitting water, disintegrating organic pollutants and photosynthesizing under visible light (Zhang et al., 2015). It is also a semiconductor and moreover highly stable under light irradiation in water solutions as well as acidic ph. (0) and alkaline solution ph. (=14) solutions due to strong covalent bonds between carbon and nitride atoms. When doped with metal precursors such as ( $\mathrm{Co}, \mathrm{Mn}, \mathrm{Cu}, \mathrm{Zn}$ or $\mathrm{W}$ ), it has been proven to obtain a high photo catalytic activity and good stability. It also has strong oxidative ability and high quantum efficiency. The functional organic metal hybrid material also exhibited its high modified electronic properties. The study was aimed at investigating the performance of graphitic carbon nitride doped with tungsten chloride in the degradation of organic dye pollutant rhodamine B dye from wastewater.

\section{Materials and Methods}

Tungsten chloride (analytical reagent), urea and ethanol (chemical pure) were purchased from Shanghai Chemical Corp. All the chemicals were of reagent grade and used without further purification. The tungsten chloride, urea and ethanol were accurately measured, mixed and grounded and heated (Table 1). The mixture was then transferred into a petri dish and maintained at room temperature for 4-6 hours to evaporate the ethanol. Thereafter, the powders were collected and placed into a semi-closed alumina crucible with a cover, then constantly heated at $550^{\circ} \mathrm{C}$ for $3 \mathrm{~h}$ in the muffle furnace with a heating rate of $15^{\circ} \mathrm{C} / \mathrm{min}$. After that, the product was then grounded into fine powder and labeled appropriately as $\mathrm{xWO}_{3} / \mathrm{g}_{-} \mathrm{C}_{3} \mathrm{~N}_{4}(\mathrm{x}-$ refer to the amount of tungsten chloride and $\mathrm{x}=0,0.05,0.15,0.25,0.4,0.5 \mathrm{mmol}$ ).

Table 1. Quantitative values off tungsten chloride, urea and ethanol used in the experiment

\begin{tabular}{|l|l|l|l|}
\hline WCL6 MOLES & WO3 IN GRAMS & PURE UREA & ETHANOL \\
\hline 0.05 & 0.0198 & $10 \mathrm{~g}$ & $10 \mathrm{ML}$ \\
\hline 0.15 & 0.0594 & $10 \mathrm{~g}$ & $10 \mathrm{ML}$ \\
\hline 0.25 & 0.099 & $10 \mathrm{~g}$ & $10 \mathrm{ML}$ \\
\hline 0.4 & 0.1584 & $10 \mathrm{~g}$ & $10 \mathrm{ML}$ \\
\hline 0.5 & 0.198 & $10 \mathrm{~g}$ & $10 \mathrm{ML}$ \\
\hline
\end{tabular}

Characterization of the structural properties of the obtained $\mathrm{WO}_{3} / \mathrm{g}-\mathrm{C}_{3} \mathrm{~N}_{4}$ composites was done by X-ray powder diffraction (XRD, Bruker D8 Advance) through $\mathrm{Cu}$ Ko radiation at voltage of $40 \mathrm{kV}$ and $40 \mathrm{~mA}$ over a temperature range of 10-80. Nitrogen adsorption-desorption was done on a nitrogen physical adsorption (Beishide 3H-2000PS4). The morphology and structure of the samples were further observed using a high-tech Transmission Electron Microscopy (TEM) (JEOL JEM-2010). The measuring of the photoluminescence spectra was done through a fluorescence spectrophotometer (F- 7000, Japan), with Xe lamp as excitation source with optical filters. The recording of the UV-vis diffuse reflectance spectra (DRS) of the samples was done through n a Shimadezu UV-2401 spectrophotometer. 


\section{Macrothink}

The evaluation of the photo catalytic activity of the $\mathrm{WO}_{3} / \mathrm{g}-\mathrm{C}_{3} \mathrm{~N}_{4}$ composites was done by observing the degradation of organic pollutant $\mathrm{RhB}$, and this was done under visible light. For each of the experiment, $30 \mathrm{mg}$ sample was dispersed into $50 \mathrm{~mL}$ of $5 \mathrm{mg} / \mathrm{L} \mathrm{RhB}$ solution with magnetic stirring. Prior to being exposed to the visible light irradiation (500 W xenon lamp) having a cutoff filter (Z N420 nm), stirring of the solution was done in a dark condition for a $\mathrm{n}$ approximate duration of $30 \mathrm{~min}$. The aim of doing that was to obtain an adsorption/desorption equilibrium between the catalyst and Rh B solution. Sampling of the two milliliters of the solution was then done after every $10 \mathrm{~min}$. To separate the catalyst, it was then centrifuged at a speed of 10000 revolutions per minute for approximately five minutes. Measurement of the concentration of $\mathrm{RhB}$ solution was then done using a UV-vis spectrophotometer at 554 rims. To help separate the catalyst $\left(\mathrm{WO}_{3} / \mathrm{G}-\mathrm{C}_{3} \mathrm{~N}_{4}\right)$ from the $\mathrm{RhB}$ organic dye solution, the $\mathrm{Rhb}$ dye and $\mathrm{WO}_{3} / \mathrm{g}-\mathrm{C}_{3} \mathrm{~N}_{4}$ sample mixture were taken to the centrifuge. Thereafter, the calculation of the degradation rate was calculated using the spectrophotometer.

\section{Results and Discussion}

\subsection{Improvement on Photo-activity}

The improvement on the photo activity was observed through the formation of a unique hetero-junction-like interfacial structure which occurred between g-C3N4 and $\mathrm{WO}_{3}$ semiconductors (Fig. 1). Technically, under the visible light exposure, both $\mathrm{g}-\mathrm{C}_{3} \mathrm{~N}_{4}$ and $\mathrm{WO}_{3}$ can be excited. This is due to the fact that the band gaps of both of them lies within the visible region. Based on that, the photo-excited electrons from the conduction band (CB) of g- $\mathrm{C}_{3} \mathrm{~N}_{4}$ would be injected into the $\mathrm{CB}$ of $\mathrm{WO}_{3}$. The injection is due to a higher favoring over potential between the $\mathrm{CB}$ edges of $\mathrm{g}-\mathrm{C}_{3} \mathrm{~N}_{4}$ and $\mathrm{WO}_{3}$. On the other hand, the movement of the photo generated holes from the valance band (VB) of $\mathrm{WO}_{3}$ towards the $\mathrm{VB}$ of $\mathrm{g}_{-} \mathrm{C}_{3} \mathrm{~N}_{4}$ occurred because of the more positive $\mathrm{VB}$ edge of $\mathrm{WO}_{3}\left(3.0 \mathrm{eV}\right.$, vs. NHE) than that of $\mathrm{g}_{-} \mathrm{C}_{3} \mathrm{~N}_{4}$ $(1.7 \mathrm{eV}$, vs. NHE). Additionally, the great reduction of the electron-hole recombination, which promote the photo catalytic reactions to decompose $\mathrm{RhB}$ occurred through the redistribution of electrons on one side of the junction $\left(\mathrm{WO}_{3}\right)$ and holes on the opposite side $\left(\mathrm{g}-\mathrm{C}_{3} \mathrm{~N}_{4}\right)$. This resulted to a higher photo catalytic activity of $\mathrm{WO}_{3} / \mathrm{g}-\mathrm{C}_{3} \mathrm{~N}_{4}$ composites than that of $\mathrm{WO}_{3}$ and the pure $\mathrm{g}-\mathrm{C}_{3} \mathrm{~N}_{4}$. Based on this outcome, it indicated a high relation between the enhanced photo catalytic activity and the hetero-junction structure and the synergetic effect at the interface between $\mathrm{g}-\mathrm{C}_{3} \mathrm{~N}_{4}$. and $\mathrm{WO}_{3}$. (Gondal et al., 2015). 


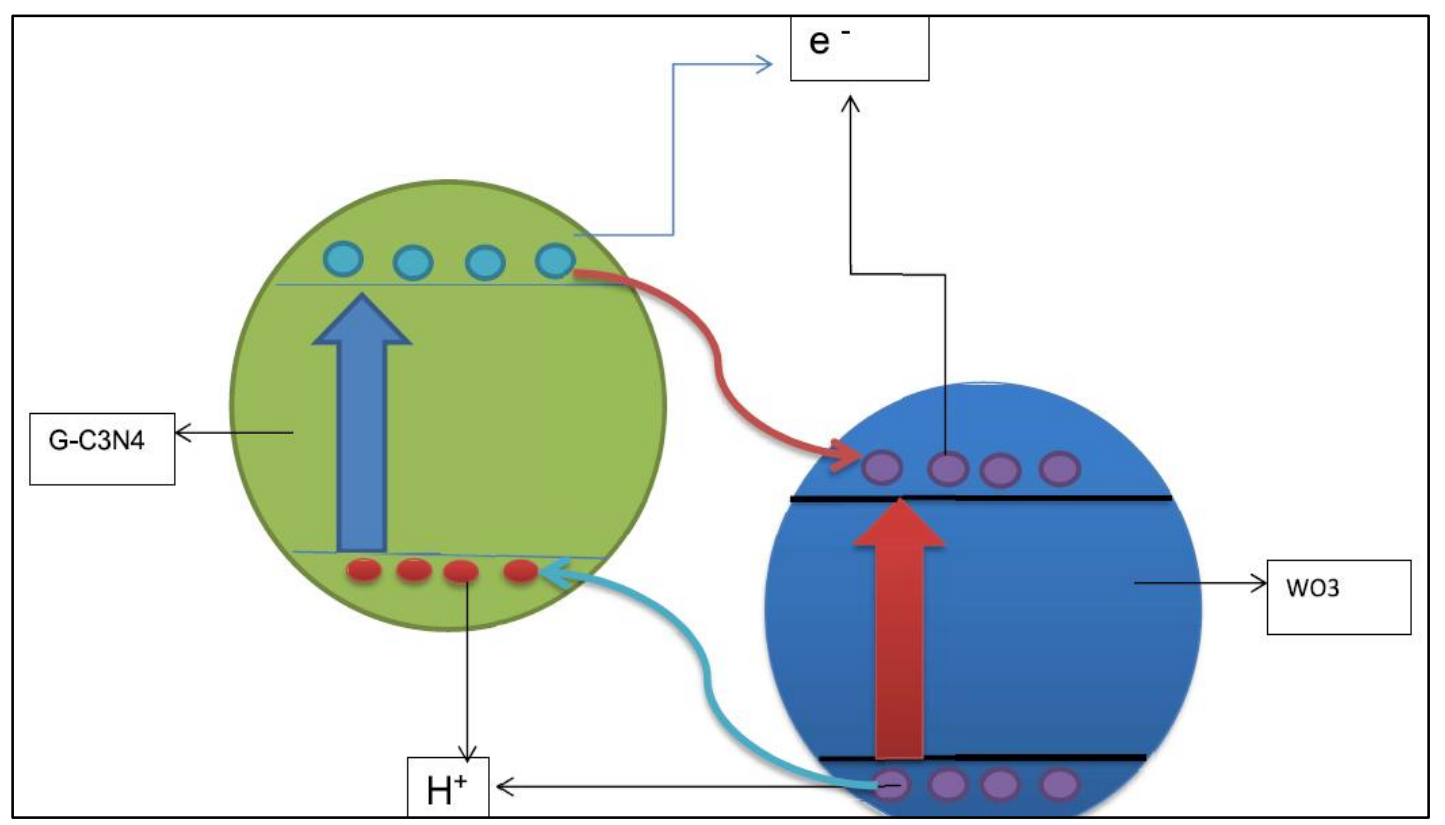

Figure 1. The indication of photo activity improvement through the formation of a unique heterojunction-like interfacial structure

\subsection{The X-ray Diffraction Patterns}

There was evidence of the difference in the structures of the sample based on the X-ray diffraction patterns indicated. This indicated that samples of $\mathrm{g}-\mathrm{C}_{3} \mathrm{~N}_{4}$ and $\mathrm{WO} / \mathrm{g}-\mathrm{C}_{3} \mathrm{~N}_{4}$ have different peaks (Fig. 2). The difference may be a a result of the different ratios of $\mathrm{WO}_{3}$ ranges (high to low), with the highest peak of $\mathrm{WO}_{3}$ being from the $0.05 \mathrm{WO}_{3} / \mathrm{g}-\mathrm{C}_{3} \mathrm{~N}_{4}$. Based on the $\mathrm{X}$-ray diffraction patterns and the 28 corresponding characteristic values of the diffraction peaks, it was shown that only the peaks attributed to $\mathrm{g}-\mathrm{C}_{3} \mathrm{~N}_{4}$ and $\mathrm{WO}_{3}$, and peaks attributed to other components were not detected. Such output provided indications of the purity of the obtained samples on degradation. The original $\mathrm{g}-\mathrm{C}_{3} \mathrm{~N}_{4}$ had two peaks which were within the $13.1^{\circ}$ and $27.6^{\circ}$. These can be indexed as (100) and (002) diffraction planes (JCPDS no. 87-1526). A $27.6^{\circ}$ pick, which was attributed to the (002) of the g-C $3 \mathrm{~N} 4$, was found within the $\mathrm{X}$-ray diffraction patterns of all the samples except the $0.5 \mathrm{WO}_{3} / g-\mathrm{C}_{3} \mathrm{~N}_{4}$ Sample. On the other hand. peaks which were attributed to the WOW (JCPDS no.83-0950) could also be observed in all the $\mathrm{WO}_{3} / \mathrm{g}-\mathrm{C}_{3} \mathrm{~N}_{4}$ composites. Based on such outcome, there was indication that the different $\mathrm{WO}_{3}$ concentrations have great impact on the phase composition. Moreover, the low-angle reflection peak which was observed at $13.1^{\circ}$ appeared less pronounced and the corresponding crystallization degree of $\mathrm{WO}_{3} / \mathrm{g}-\mathrm{C}_{3} \mathrm{~N}_{4}$ composites was observed to slightly decreased with the increase in the $\mathrm{WO}_{3}$ concentration. This occurred due to the introduced ion which had an alleviation on the crystallization process during the process of calcination. This finding was in agreement with studies by (Zhang et al., 2015; Wang et al., 2018) which indicated that the enhanced photocatalytic activity should benefit from the narrow band gap, fast separation rate of photogenerated carriers and enhanced absorption in visible light range. These proved that the work provides a promising approach to improving the performance of visible light-driven catalysts in the fabrication of other photocatalysts for improved wastewater purification. 


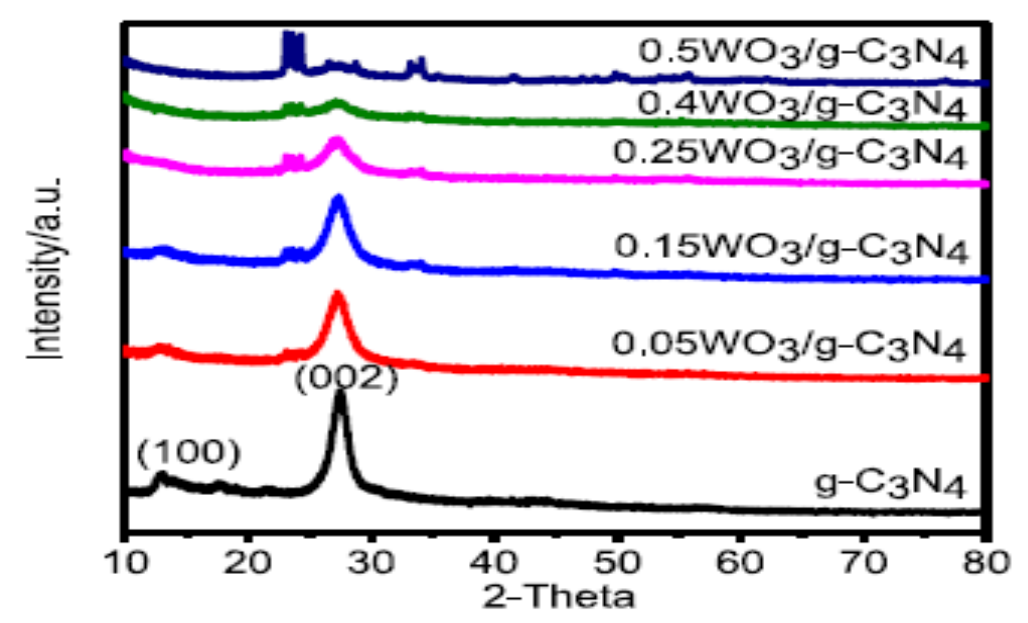

Figure 2. X-ray diffraction patterns of the $\mathrm{WO}_{3} / \mathrm{g}-\mathrm{C}_{3} \mathrm{~N}_{4}$ samples with different $\mathrm{WO}_{3}$ concentration

\subsection{Morphological Analysis}

The investigation of the samples morphology was done by SEM and the outcome presented in Figure 3 (a) bare $g-C_{3} N_{4}$, which indicated a difference in particle size from sample in figure (b) which represented $0.25 \mathrm{WO}_{3} / \mathrm{g}-\mathrm{C}_{3} \mathrm{~N}_{4}$. Indeed, the treated figure (b) sample exhibited some particle agglomeration to a certain degree. Moreover, it is evident that in figure (b) 0.25 $\mathrm{WO}_{3} / \mathrm{g}-\mathrm{C}_{3} \mathrm{~N}_{4}$ sample, the occurred well deposition of the $\mathrm{WO}_{3}$ on the sheet-like $\mathrm{g}-\mathrm{C}_{3} \mathrm{~N}_{4}$. Going by such revelation, there was good inter-facial contact between $\mathrm{g}-\mathrm{C}_{3} \mathrm{~N}_{4}$ and $\mathrm{WO}_{3}$ which will be beneficial in separately transferring the photo excited carriers within the photo catalysis. The observation of the morphology of the bare $\mathrm{g}-\mathrm{C}_{3} \mathrm{~N}_{4}$ and the representative $0.25 \mathrm{WO}_{3} / \mathrm{g}-\mathrm{C}_{3} \mathrm{~N}_{4}$ sample was also undertaken through TEM. The result showed that the bare g- $\mathrm{C}_{3} \mathrm{~N}_{4}$ formed a sheet like structure that consisted of wrinkles that formed due to the aggregation and gathering of the $\mathrm{g}-\mathrm{C}_{3} \mathrm{~N}_{4}$ sheets. The representative of the $0.25 \mathrm{WO}_{3} / g-\mathrm{C}_{3} \mathrm{~N}_{4}$ sample had a particle size hat ranged between $40-50 \mathrm{~nm}$, as well as a worm-like pore structure. Furthermore, the $\mathrm{WO}_{3}$ particles were showed to cover the $\mathrm{g}-\mathrm{C}_{3} \mathrm{~N}_{4}$ surface, which were almost in direct contact with the $\mathrm{g}-\mathrm{C}_{3} \mathrm{~N}_{4}$ surface which lacked the agglomeration. The interaction between the $\mathrm{WO}_{3}$ and $\mathrm{g}-\mathrm{C}_{3} \mathrm{~N}_{4}$ was so strong that these particles could not peel off from the $\mathrm{g}-\mathrm{C}_{3} \mathrm{~N}_{4}$ surface. This outcome could not only improve the dispersion property of the materials but also offer additional photocatalytic reaction sites. Indeed, there was further confirmation of the elemental information of the as-prepared $0.25 \mathrm{WO}_{3} / \mathrm{g}_{-} \mathrm{C}_{3} \mathrm{~N}_{4}$ nano-composite of the EDX spectrum that the introduced $\mathrm{W}$ species have been doped in the lattice of $\mathrm{g}-\mathrm{C}_{3} \mathrm{~N}_{4}$ Sample. This provided a reliable indication that the successful formation of the nano-composite with high purity had been achieved. Indeed, the finding was in concurrence with what oher studies has reported (Zhang et al., 2015; Wang et al., 2018). 


\section{Ml Macrothink}
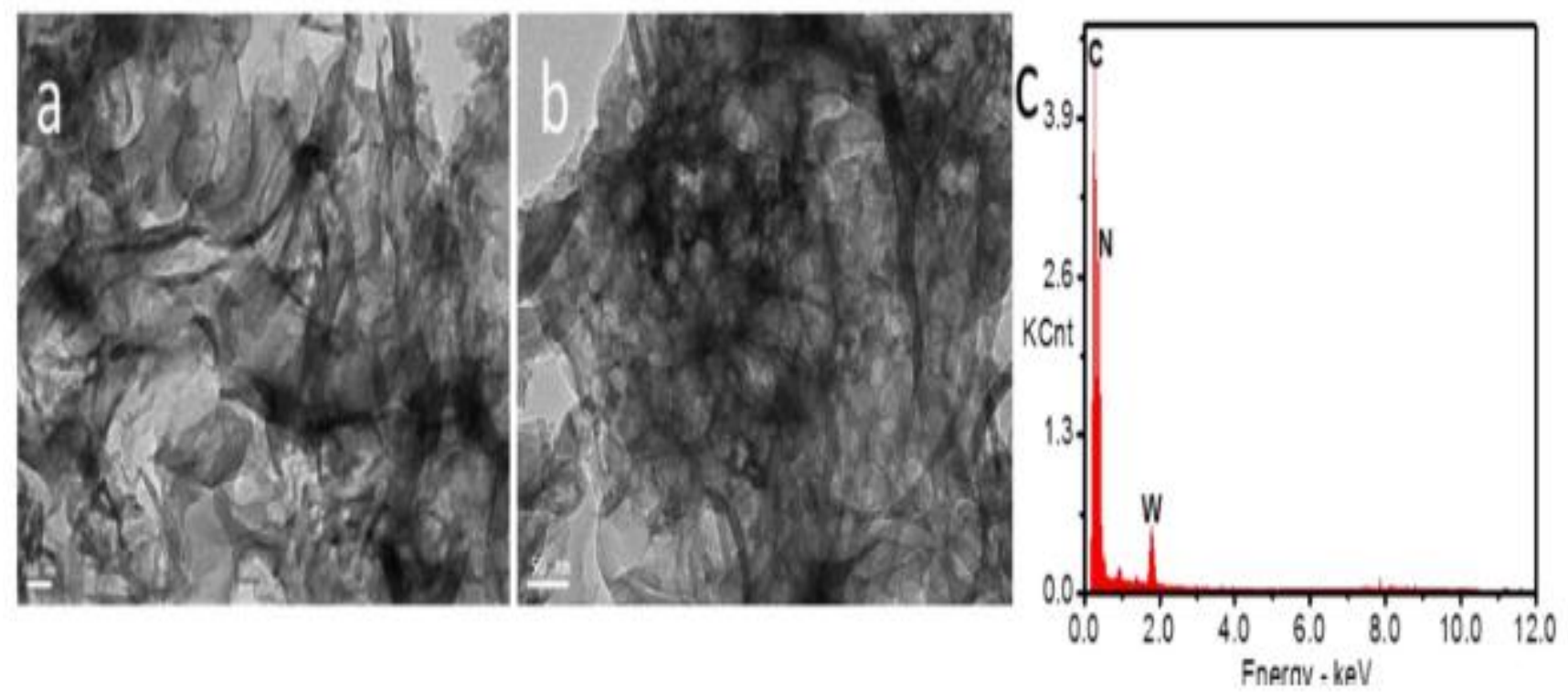

Figure 3. TEM images of (a) bare $\mathrm{g}-\mathrm{C}_{3} \mathrm{~N}_{4}$ and (b) the representative $0.25 \mathrm{WO}_{3} / g-\mathrm{C}_{3} \mathrm{~N}_{4}$; (c) EDX spectrum of the $0.25 \mathrm{WO}_{3} / \mathrm{g}-\mathrm{C}_{3} \mathrm{~N}_{4}$ Sample

\subsection{The Nitrogen Adsorption-desorption Isotherms on the Brunauer-Emmett-Teller Surface} Area

The Nitrogen adsorption- desorption isotherms was used to calculate the Brunauer-EmmettTeller surface area (SBET) of the $\mathrm{WO}_{3} / \mathrm{g}-\mathrm{C}_{3} \mathrm{~N}_{4}$ samples and the results are presented in Fig. 4 . The classification of the Nitrgen adsorption-desorption isotherms of the $\mathrm{WO}_{3} / g-\mathrm{C}_{3} \mathrm{~N}_{4}$ was done and grouped as 4 in the International Union of Pure and Applied Chemistry classification (Wang et al., 2018). This suggested the presence of mesopores, which is consistent with the result observed by transmission electron microscopy. There was an association between the hysteresis loop in the low-pressure range $\left(0.4<\mathrm{P} / \mathrm{P}_{0}<0.9\right)$ and the intra-aggregated pores. Additionally, there was a relation between the high- pressure hysteresis loop $\left(0.9<\mathrm{P} / \mathrm{P}_{0}<1\right)$ with the to the larger pores formed between secondary particles. There was an indication that all the samples possess pore size distributions centered between 30 and $40 \mathrm{~nm}$ as a result of the obtained pore size distribution curves from an analysis of desorption branch of the isotherms. The Brunauer-Emmett-Teller analysis run under this study was intended to explain the physical adsorption of nitrogen gas molecules on surface of the obtained composites. From that occurrence, it served as the basis for an important analysis technique for the measurement of the specific surface area of the $\mathrm{g}-\mathrm{C}_{3} \mathrm{~N}_{4}$ composites. Moreover, it was found that the specified surface area of the samples was not directly proportional to the observed pore size increment. Despite such occurrence, a little effect on photo catalytic activity occurred, furthermore, the entire band gap energies were all shown to be within the same range (Table 2). 


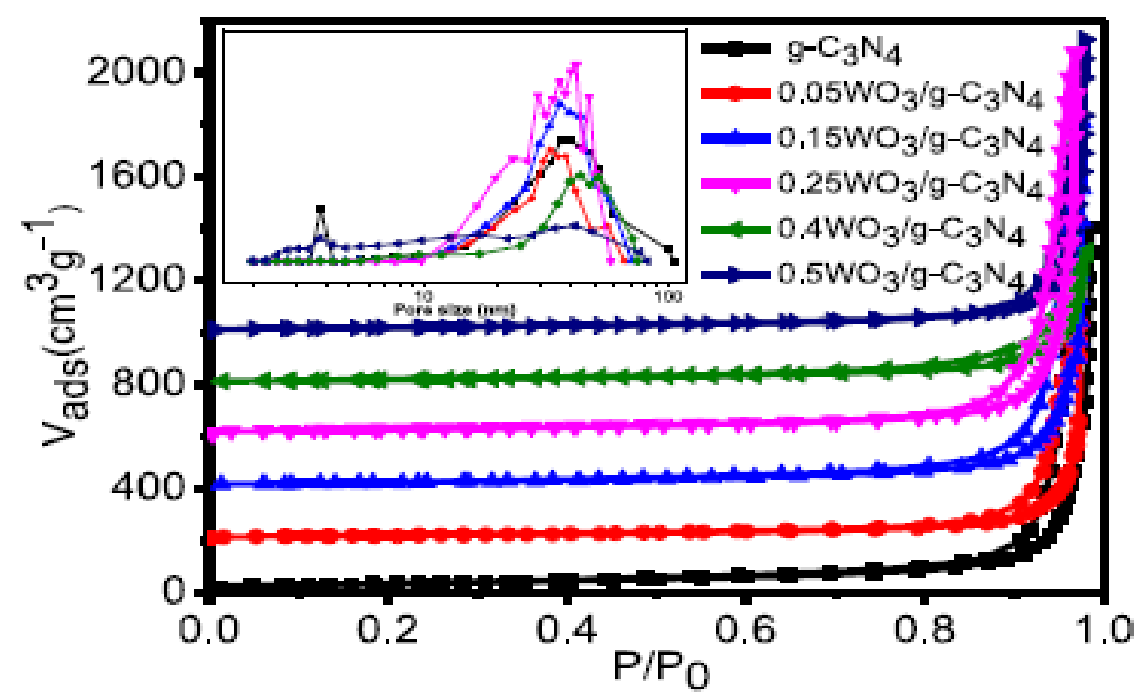

Figure 4. TheBrunauer-Emmett-Teller surface area through N2 adsorption-desorption isotherms

Table 2. The sample pore sizes description

\begin{tabular}{|l|l|l|l|l|}
\hline Sample identity & $\begin{array}{l}\text { Surface area } \\
\text { in }(\mathrm{M} 2 / \mathrm{g})\end{array}$ & $\begin{array}{l}\text { Pore size } \\
\text { in }(\mathrm{nm})\end{array}$ & $\begin{array}{l}\text { Pore volume } \\
\text { in }(\mathrm{cm} 2 / \mathrm{g})\end{array}$ & Eg in $(\mathrm{eV})$ \\
\hline $\mathrm{g}-\mathrm{C} 3 \mathrm{~N} 4$ & 117.5 & 34.7 & 2.081 & 2.8 \\
\hline $0.05 \mathrm{WO}_{3} / \mathrm{g}-\mathrm{C}_{3} \mathrm{~N}_{4}$ & 68.1 & 31.9 & 1.366 & 2.57 \\
\hline $0.15 \mathrm{WO}_{3} / \mathrm{g}-\mathrm{C}_{3} \mathrm{~N}_{4}$ & 84.6 & 34.4 & 2.312 & 2.62 \\
\hline $0.25 \mathrm{WO}_{3} / \mathrm{g}-\mathrm{C}_{3} \mathrm{~N}_{4}$ & 100.9 & 41.1 & 2.478 & 2.73 \\
\hline $0.4 \mathrm{WO}_{3} / \mathrm{g}-\mathrm{C}_{3} \mathrm{~N}_{4}$ & 72.7 & 39.5 & 1.831 & 2.52 \\
\hline $0.5 \mathrm{WO}_{3} / \mathrm{g}-\mathrm{C}_{3} \mathrm{~N}_{4}$ & 70.5 & 38 & 1.746 & 2.4 \\
\hline
\end{tabular}

\subsection{The UV-vis Diffuse Reflectance Spectroscopy on the Optical Properties}

The examination of the optical properties of the g- $\mathrm{C}_{3} \mathrm{~N}_{4}$ and $\mathrm{WO} / \mathrm{g}-\mathrm{C}_{3} \mathrm{~N}_{4}$ composite samples in range of 200-700 nm was done using UV-vis diffuse reflectance spectroscopy. The results are presented in Fig. 5 (a) and (b). Based on this examination run, all the samples were observed to exhibit absorbance within the visible light region. Moreover, the estimation of the visible absorption range was done and found to be at around $480 \mathrm{~nm}$. The UV-vis spectrum of the $\mathrm{WO} / \mathrm{g}-\mathrm{C}_{3} \mathrm{~N}_{4}$ was able to exhibit a red shift as well as a significant adsorption at within 250 $-700 \mathrm{~nm}$. The shift and adsorption wavelength also increased with the increase in $\mathrm{WO}_{3}$ concentration. Such a shift and adsorption wavelength were an indication of the existence of the interaction between the g- $\mathrm{C}_{3} \mathrm{~N}_{4}$ and $\mathrm{WO} / \mathrm{g}-\mathrm{C}_{3} \mathrm{~N}_{4}$ composite samples. Such finding provided a reliable prove that the $\mathrm{WO} / \mathrm{g}-\mathrm{C}_{3} \mathrm{~N}_{4}$ composites is indeed a very good photocatalyst for the visible light driven applications with enhanced absorption ability. This result was matching the findings that were achieved and reported by Lin et al., (2017). 

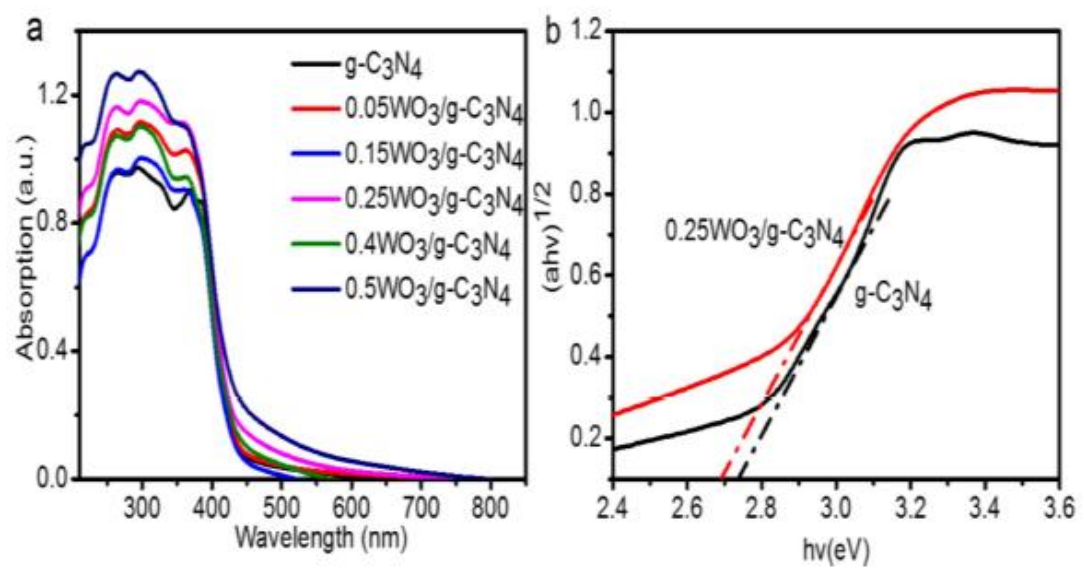

Figure 5. The Ultraviolet-vis diffuse reflectance spectroscopy on the optical properties

The room temperature photoluminescence spectra of the bare $\mathrm{g}-\mathrm{C}_{3} \mathrm{~N}_{4}$ and the representative $0.25 \mathrm{WO}_{3} / \mathrm{g}-\mathrm{C}_{3} \mathrm{~N}_{4}$ samples are provided in Fig. 6. The photoluminescence emission spectra are significant in the determination of the efficiency of charge carrier trapping, migration, and separation. This also help in the investigation of the fate of photogenerated electron-hole pairs. From the study, both the samples indicated a single kind of broad luminescence peak. The luminescence peak was found to be centered at approximately $450 \mathrm{~nm}$ with the peak position having some shift. The observed emission peak was directly originating from the band-to-band transitions and the shift of the peak position was consistent with variation of band gap energy of both the samples. Indeed, there was an observed decrease in the photoluminescence intensity of $0.25 \mathrm{WO}_{3} / \mathrm{g}-\mathrm{C}_{3} \mathrm{~N}_{4}$ as compared to the decrease within the bare $\mathrm{g}-\mathrm{C}_{3} \mathrm{~N}_{4}$. This observation was an indication the recombination of the electron-hole pairs was moderately inhibited or the charge separation has a significant accelerated on the $0.25 \mathrm{WO}_{3} / \mathrm{g}-\mathrm{C}_{3} \mathrm{~N}_{4}$ sample. This further implied that the nanocomposite had lower recombination rates of electrons and holes under visible light irradiation. This finding further proves that the photo-induced electrons flow from $\mathrm{g}-\mathrm{C}_{3} \mathrm{~N}_{4}$ to $\mathrm{WO}_{3}$, causing photoluminescence quenching of $\mathrm{g}-\mathrm{C}_{3} \mathrm{~N}_{4}$ with $\mathrm{WO}_{3}$, thereby preventing the direct recombination of electron-hole pairs. Indeed, Lin et al., (2017) identified the need to for the design and synthesis of high-performance photocatalysts with highly-efficient charge separation.

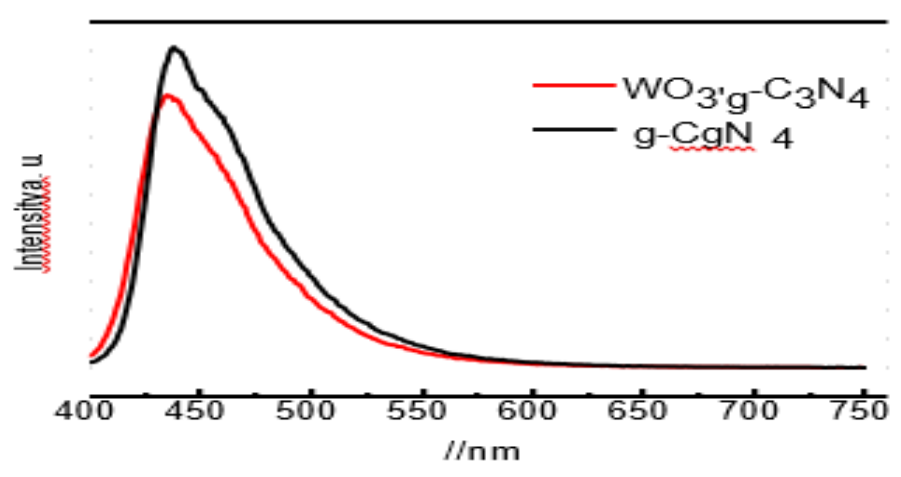

Figure 6. Photocatalytic emission spectra 


\section{Macrothink \\ Environmental Management and Sustainable Development \\ ISSN 2164-7682 \\ 2019, Vol. 8, No. 2}

\subsection{RhB Degradation Through Photocatalytic Activities}

The result on photocatalytic activities for $\mathrm{RhB}$ degradation over the $\mathrm{WO}_{3} / \mathrm{g}-\mathrm{C} 3 \mathrm{~N}_{4}$ composites samples with different $\mathrm{WO}_{3}$ content were carried out under visible light irradiation the result presented in Fig. 7. The normalized concentrations are provided as $\mathrm{C} / \mathrm{Co}$ (where $\mathrm{C}$ and Co are the concentration at the reaction time $\mathrm{t}$ and the initial $\mathrm{RhB}$ concentration). The blank test experiment indicated that the concentration of $\mathrm{RhB}$ experience little decrease (removal of only $2 \%$ ) without any photocatalyst under visible-light irradiation. This proved that the photoinduced self-decomposition can be neglected in comparison with the photocatalysis that is brought about by various existing catalyst particles. Furthermore, prior to the visible-light irradiation, the mixture containing the catalyst and Rhb was thoroughly mixed by being stirred in the dark for 30 minutes until an adsorption equilibrium was achieved. All the materials had a relatively similar adsorption capacity which was in the range of $10 \%-12 \%$ of $\mathrm{C} / \mathrm{Co}$ in the dark. In comparison to the blank test, it was observed that there was difference in the decrease in the $\mathrm{C} / \mathrm{Co}$ of $\mathrm{WO}_{3} / \mathrm{g}-\mathrm{C}_{3} \mathrm{~N}_{4}$ composites samples under visible light. Furthermore, the best photocatalytic activity of $\mathrm{WO}_{3} / \mathrm{g}-\mathrm{C}_{3} \mathrm{~N}_{4}$ was obtained when the content of $\mathrm{WO}_{3}$ was at 0.25 . Through experimentally increasing the $\mathrm{WO}_{3}$ content from 0 to 0.25 , there was a consequential increase in the photocatalytic activity of $\mathrm{WO}_{3} / \mathrm{g}-\mathrm{C}_{3} \mathrm{~N}_{4}$. Such increase may be attributed to the which may be due to the presence of $\mathrm{g}-\mathrm{C}_{3} \mathrm{~N}_{4}$ in the materials. Through further increase in the content of $\mathrm{WO}_{3}$, the photocatalytic activity of $\mathrm{WO}_{3} / \mathrm{g}-\mathrm{C}_{3} \mathrm{~N}_{4}$ also decreased to a level that was even poorer than the bare $\mathrm{g}-\mathrm{C}_{3} \mathrm{~N}_{4}$. Such manifestation may be related with the aggregated $\mathrm{WO}_{3}$ particles at the surface of $\mathrm{g}-\mathrm{C}_{3} \mathrm{~N}_{4}$ that leads to the decrease in the photocatalytic capacity. Therefore, such occurrence shows that the optimal $\mathrm{WO}_{3}$ content was 0.25 in the $\mathrm{WO}_{3} / \mathrm{g}-\mathrm{C}_{3} \mathrm{~N}_{4}$ samples, where the best activity was displayed and nearly $100 \%$ of $\mathrm{RhB}$ decomposition and degradation within $2 \mathrm{~h}$ of visible-light irradiation was realized. Indeed, Shivatharsiny et al., (2015) suggested that the periodic mesoporous materials can be used as adsorbents and photocatalysts for the removal of dye molecules from aqueous solutions with high efficiency, a suggestion that also agree with the findings from the present study.

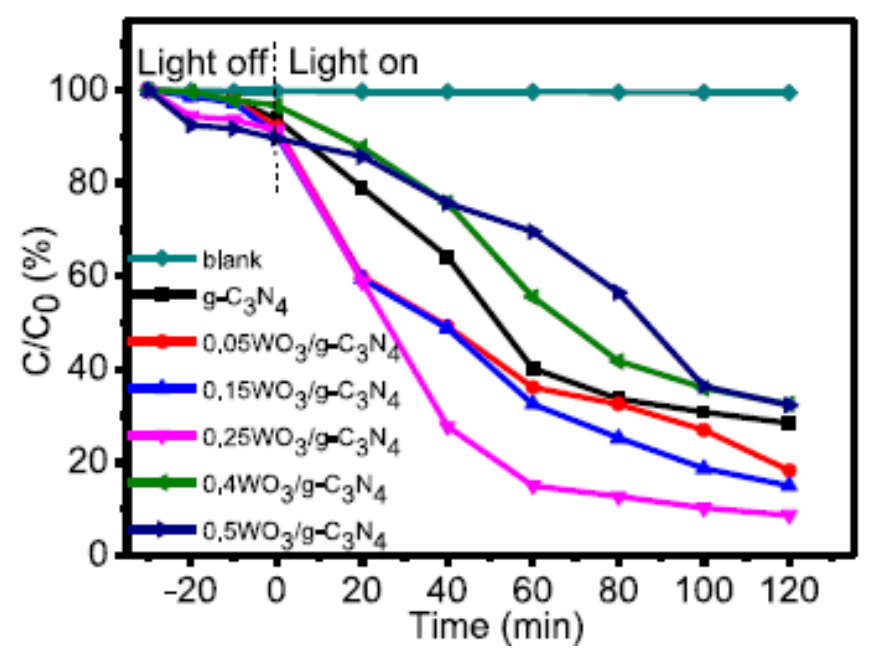

Figure 7. Photocatalytic activities for $\mathrm{RhB}$ degradation over the $\mathrm{WO}_{3} / \mathrm{g}-\mathrm{C} 3 \mathrm{~N}_{4}$ composites samples with different $\mathrm{WO}_{3}$ content 


\section{Conclusion}

Based on the findings from this study, the as-prepared hybrid photo catalyst has proved to having a greater ability to improve the photo degradation performance because of accompanying synergetic effect. Indeed, the photo excited electrons from $\mathrm{g}-\mathrm{C}_{3} \mathrm{~N}_{4}$ were noted to be efficiently separated and were injected to the conductive band of the $\mathrm{WO}_{3}$. The highest photo activity was achieved for the optimum ratio of $0.25 \mathrm{WO}_{3} / \mathrm{g}-\mathrm{C}_{3} \mathrm{~N}_{4}$. The hybrid catalyst equally showed stability and high efficiency in the photo degradation process. Moreover, the composite further demonstrated a high activity for degradation of $\mathrm{RhB}$ under visible light irradiation. The presence of $\mathrm{g}-\mathrm{C}_{3} \mathrm{~N}_{4}$ proved to be beneficial for enhancement in photo catalytic activity of the $\mathrm{g}-\mathrm{C}_{3} \mathrm{~N}_{4}-\mathrm{WO}_{3}$ composite and provided one of the best alternative modes of degrading organic dye pollutant Rhodamine $\mathrm{B}$ dye from wastewater.

\section{Acknowledgement}

We greatly appreciate the School of Environmental College of Tongji University for supporting the study through provision of laboratory space and other facilities.

\section{References}

Boniface, P. K., \& John, G. (2002). Preventing and Resolving Water Use Conflicts in the Mount Kenya Highland-Lowland System through Water Users' Associations. Mountain Research and Development, 22(4), 332-337.

https://doi.org/10.1659/0276-4741(2002)022[0332:PARWUC]2.0.CO;2

Donde, O. O., Cuicui, T., Yingying, T., \& Bangding, X. (2018). Efficacy of macrophyte dominated wastewater inclosure as post-treatment alternative in domestic wastewater quality polishing for eradication of faecal pathogenic bacteria pollution. Process Safety and Environmental Protection, 114, 192-205. https://doi.org/10.1016/j.psep.2017.12.023

Donde, O. O., Ojwang, O. W., Muia, A. W., \& Wanga, L. A. (2014). Bacterial abundance on the skin, gills and intestines of Cyprinus carpio in Lake Naivasha, Kenya: Implications for public health and fish quality. Lakes and Reservoirs: Research and management. http://doi.org/10.1111//re.12050

Ekevwe, A., Aloba, I., \& Doka, G. M. (2017). Proximate Evaluation of Organic Pollutants in Onion Plants Cultivated Along the Bank of River Jakara Kano State of Nigeria. Advances in Biochemistry, 5(3), 41-46. https://doi.org/10.11648/j.ab.20170503.12

Gondal, M. A., Adesida, A. A., Rashid, S. G., Shi, S., Khan, R., Yamani, Z. H., Shen, K., Xu, Q., Seddigi, Z., \& Chang, X., (2015). Preparation of WO3/g-C3N4 composites and their enhanced photodegradation of contaminants in aqueous solution under visible light irradiation. Reaction Kinetics, Mechanisms and Catalysis, 114(1), 357-367.

https://doi.org/10.1007/s11144-014-0787-y

Lin, B., An, H., Yan, X., Zhang, T., Wei, J., \& Yang, G. (2017). Fish-scale structured g-C3N4 nanosheet with unusual spatial electron transfer property for high-efficiency photocatalytic hydrogen evolution. Applied Catalysis B: Environmental, 210, 173-183. 
https://doi.org/10.1016/j.apcatb.2017.03.066

Pang, Y., Huang, J., Xi, J., Hu, H., \& Zhu, Y. (2016). Effect of ultraviolet irradiation and chlorination on ampicillinresistant Escherichia coli and its ampicillin resistance gene. Front Environ Sci Eng., 10, 522-530. https://doi.org/10.1007/s11783-015-0779-9

Ping, T., Yuanlu, X., Chengwen, S., Yanyan, Y., Zaili, Y., Shihong, W., .. Mihua, S. (2017). A novel strategy for the removal of rhodamine $\mathrm{B}(\mathrm{RhB})$ dye from wastewater by coal-based carbon membranes coupled with the electric field. Separation and Purification Technology, 79, 175-183. https://doi.org/10.1016/j.seppur.2017.02.014

Rop, K. R., Donde, O. O., Muia, A. W., \& Makindi, S. M. (2016). Influence of rainfall intensity on faecal contamination in River Nyangores of Mara Basin, Kenya: An eco-health integrity perspective. Asian Jr. of Microbiol. Biotech. Env. Sc., 18(2), 281-289.

Rop, K. R., Muia, A. W., Makindi, S., \& Donde O. O. (2014). Changes in the densities of faecal and organic matter contaminants from upstream to downstream along Nyangores river of Mara Catchment, Kenya. Journal of Environmental Science and Water Resources, 3(1), 015-25.

Shivatharsiny, R., Rui, P., \& Ranjit, T. K. (2015). An insight into the adsorption and photocatalytic degradation of rhodamine $\mathrm{B}$ in periodic mesoporous materials. Applied Catalysis B: Environmental, 174, 49-59. https://doi.org/10.1016/j.apcatb.2015.02.040

Sieliechi, J. M., Kayem, G. J., \& Sandu, I. (2010). Effect of water treatment residuals (aluminium and iron ions) on human health and drinking water distribution systems. Inter J. Conserv Sci., 1(3), 175-182.

Sun, D., \& Yang, X. (2017). Rapid Determination of Toxic Rhodamine B in Food Samples Using Exfoliated Graphene-Modified Electrode. Food Anal. Methods, 10, 2046-2052. https://doi.org/10.1007/s12161-016-0773-2

U.S. Global Change Research Program. (2016). The Impacts of Climate Change on Human Health in the United States: A Scientific Assessment. U.S. Global Change Research Program, Washington, DC. 312p.

Wang, Y., Zhao, S., Zhang, Y., Fang, J., Zhou, Y., Yuan, S., Zhang, C., \& Chen, W. (2018). One-pot synthesis of K-doped g-C3N4 nanosheets with enhanced photocatalytic hydrogen production under visible-light irradiation. Applied Surface Science, 440, 258-265. https://doi.org/10.1016/j.apsusc.2018.01.091

Zhang, M., Bai, X., Liu, D., Wang, J., \& Zhu, J. (2015). Enhanced catalytic activity of potassium-doped graphitic carbon nitride induced by lower valence position. Applied Catalysis B: Environmental, 164, 77-81. https://doi.org/10.1016/j.apcatb.2014.09.020 


\section{Macrothink \\ Environmental Management and Sustainable Development \\ ISSN 2164-7682}

\section{Copyright Disclaimer}

Copyright for this article is retained by the author(s), with first publication rights granted to the journal.

This is an open-access article distributed under the terms and conditions of the Creative Commons Attribution license (http://creativecommons.org/licenses/by/3.0/). 